Блаженкова Ю. П.

ВОЛОНТЕРСКОЕ ДВИЖЕНИЕ КАК ЭЛЕМЕНТ РАЗВИТИЯ СОВРЕМЕННЫХ МУЗЕЙНЫХ КОММУНИКАЦИЙ

(НА ПРИМЕРЕ БИБЛИОТЕКИ ПРИМОРСКОЙ ГОСУДАРСТВЕННОЙ КАРТИННОЙ ГАЛЕРЕИ)

Блаженкова Ю. П.

Yu. P. Blazhenkova

ВОЛОНТЕРСКОЕ ДВИЖЕНИЕ КАК ЭЛЕМЕНТ РАЗВИТИЯ СОВРЕМЕННЫХ МУЗЕЙНЫХ КОММУНИКАЦИЙ (НА ПРИМЕРЕ БИБЛИОТЕКИ ПРИМОРСКОЙ ГОСУДАРСТВЕННОЙ КАРТИННОЙ ГАЛЕРЕИ)

\title{
VOLUNTEER MOVEMENT AS AN ELEMENT OF DEVELOPMENT OF MODERN MUSEUM COMMUNICATIONS (ON THE EXAMPLE OF THE LIBRARY OF THE PRIMORY STATE PICTURE GALLERY)
}

Блаженкова Юлия Павловна - заведующий научно-просветительским отделом КГАУК «Приморская государственная картинная галерея» (Россия, Владивосток). E-mail: lib_primgallery@mail.ru.

Ms. Yuliya. P. Blazhenkova - Head of the Scientific and Educational Department of the Primorsky State Picture Gallery (Russia, Vladivostok).E-mail: lib_primgallery@mail.ru.

Аннотация. Статья посвящена возникновению и современному состоянию волонтерского движения в музеях мира, основным проблемам и направлениям его развития в современной культуре.

Summary. The article is devoted to the emergence of the status of the volunteer movement in museums of the world, the main problems and directions of its development in modern culture.

Ключевые слова: музей, картинная галерея, библиотека, искусство, культура, просветительская деятельность, волонтер.

Key words: museum, art gallery, library, art, culture, enlightenment, volunteer.

УДК 069:01/069:002

Концепция привлечения волонтеров (добровольных помощников) в учреждения культуры не нова. Зарубежные музеи ввели данное направление в свою основную работу начиная с рубежа 1980-х гг., некоторые английские музеи - с 1960-х гг. Лидерами выступили также музеи США, Германии, других европейских стран. Научно-исследовательский комплекс Смитсоновского института привлек около 6,3 тыс. волонтеров. Ярким примером стал запуск Музеем науки и промышленности в Чикаго программы по поиску «любознательных и отважных» волонтеров, готовых 30 дней, с 20 октября по 18 ноября 2010 г., прожить в стенах музея и поделиться своими впечатлениями в социальных сетях (Facebook и Twitter). Молодым людям из Германии в возрасте от 18 до 26 лет предоставляется возможность на протяжении шести либо двенадцати месяцев работать в рамках политики в области культуры и образования [2].

Популяризация волонтерского движения, эффективный волонтерский менеджмент за несколько десятков лет превратили эпизодические и неорганизованные добровольческие практики в мощное организованное волонтерское движение в сфере культуры. Например, в государственной галерее Штутгарта сегодня работает более 70 волонтеров при штате музейного персонала в 11 человек. Их деятельность чаще всего связана с функциями связи с общественностью: улучшения сервиса для посетителей, PR, реклама, поиск новых членов Клуба друзей музея, работа с престарелыми и пенсионерами, проведение экскурсий в музее, распространение музейных информационных материалов. Они следят за исправностью аудиогидов, работают смотрителями во время проведения больших выставок, налаживают контакты музея с широким кругом партнеров.

Сегодня существует международная волонтерская служба в сфере внешней политики в области культуры и образования - «Kulturweit» (культура без границ). Деятельность службы планируется и координируется Германским комитетом по делам ЮНЕСКО при финансовой поддержке Федерального министерства иностранных дел. 


\section{Учёные записки}

Комсомольского-на-Амуре государственного технического университета

Расширили свой штат добровольцами и передовые российские музеи.

Государственный Эрмитаж в 1996 г. впервые применил в своей культурно-просветительской программе проекты с участием волонтеров, а в 2003 г. была создана Служба волонтеров для помощи в дни празднования юбилея Санкт-Петербурга. Таким образом, работа была выведена на новый качественный уровень и оказала существенную помощь в работе сотрудникам Государственного Эрмитажа в период масштабных юбилейных мероприятий. Руководство службой волонтеров Государственного Эрмитажа взял на себя Михаил Кожуховский [1].

В 2011 г. начал работу с волонтерами Политехнический музей; сначала только на больших проектах, а после расширения практика вовлечения волонтеров (от 30 до 150 чел.) стала еженедельной.

Сообщество волонтеров Государственной Третьяковской галереи было создано весной 2012 г. и насчитывает более 250 участников.

В рамках эксперимента Департамента культуры Москвы Первый волонтерский центр по развитию волонтерского движения в столичных музеях и галереях, осваивающих успешный опыт США, открылся в 2015 г. в Государственном музее истории ГУЛАГа. Волонтерам предложили участвовать в проведении выставок, лекций и концертов, работать с архивными документами, переводить материалы на иностранные языки и помогать людям, пострадавшим от сталинских репрессий. Социально-волонтерский центр музея истории ГУЛАГа формирует особое сообщество людей, желающих в свое свободное время оказывать квалифицированную помощь музею и его аудитории. В этом же году восемь ведущих музеев в Москве (Государственная Третьяковская галерея, Политехнический музей, Государственный Дарвиновский музей, Государственный музей истории ГУЛАГа, Московский музей современного искусства, мультимедиа Арт Музей, музейное объединение «Музей Москвы», музей современного искусства «Гараж») разработали специальную карту, дающую право бесплатного прохода на крупнейшие площадки и постоянные экспозиции музеев участвующим в программе. Такие бонусы, несомненно, привлекут новых желающих стать волонтером.

В феврале 2015 г. в городе Сочи состоялся «I Всероссийский форум добровольцев», в рамках деятельности которого были определены четыре приоритетных направления развития добровольчества в России, одним из которых стало культурное волонтерство. Анализ современного состояния культурного волонтерства позволил обозначить ключевые проблемы в его организации: информационный вакуум вокруг волонтерской деятельности в культурной сфере, отсутствие социального заказа на культурное волонтерство (неготовность учреждений культуры к применению волонтерской работы), отсутствие готовых моделей взаимодействия между учреждениями культуры и волонтерами на основных культурных площадках, отсутствие региональной системы развития и управления культурным волонтерством; отсутствие определения статуса волонтеров (волонтерские книжки, льготы). Для решения озвученных проблем необходимо создать благоприятную среду для развития культурного волонтерства, а именно: создать моду/тренд на культуру (посещение театров, музеев и т.д.); привлечь СМИ к информированию о культурных площадках; сформировать «клубную» культуру (региональную, районную и т.д.); создать модели и технологии развития «семейных клубов» (курсы для детей и родителей); сформировать единый канал информирования о культурных мероприятиях по принципу «одного окна» (портал госуслуг (gosuslugi.ru), ссылки, социальные сети, региональные СМИ и т.д.); создать модели взаимодействия для культурных площадок; уточнить волонтерский статус (учитывать «волонтерский стаж» в качестве практики) [4].

Некоторые музеи, например государственный мемориальный природный заповедник «Музей-усадьба Л. Н. Толстого “Ясная Поляна”", разработали специальные проекты. «Музейный добровольческий десант» - проект волонтерского лагеря на базе летнего лагеря. В течение года планировались три волонтерские смены. В программе волонтерского лагеря - знакомство с историей толстовской усадьбы и традициями семьи Толстых, лекции и экскурсии, театральные и танцевальные мастер-классы, социологические опросы и помощь местным жителям, участие в музейных праздниках и культурных событиях. 
Блаженкова Ю. П.

ВОЛОНТЕРСКОЕ ДВИЖЕНИЕ КАК ЭЛЕМЕНТ РАЗВИТИЯ СОВРЕМЕННЫХ МУЗЕЙНЫХ КОММУНИКАЦИЙ (НА ПРИМЕРЕ БИБЛИОТЕКИ ПРИМОРСКОЙ ГОСУДАРСТВЕННОЙ КАРТИННОЙ ГАЛЕРЕИ)

Активно продвигается программа волонтерства в Дарвиновском музее. Волонтеров учат принимать и консультировать посетителей, привлекают к организационной поддержке музейных мероприятий, в том числе вернисажей, выставок, к проведению социологических исследований (анкетированию посетителей), секретарской и курьерской работе, к продвижению музея в Сети.

В других регионах России можно также отметить успешные примеры использования добровольчества в учреждениях культуры. Ассоциация музейных волонтеров города Нижневартовска является добровольным общественным объединением руководителей и представителей активов школьных музеев. Целью создания и деятельности ассоциации является сохранение исторического и культурного наследия посредством формирования единого музейного пространства, тесного сотрудничества школьных музеев города через организацию совместных семинаров, конференций и выездных экскурсий. Ассоциация стремится к повышению гражданской активности подростков и молодежи через изучение музейного дела, экскурсионную программу, проектную деятельность.

Большое значение музеи страны придают системе поощрений волонтеров, что позволяет повысить активность и качество работы добровольцев, более объективно оценивать выполняемую работу по степени вовлеченности в деятельность на различных уровнях, начиная от участия в проекте вплоть до его курирования, а также развивать такие социально значимые качества личности, как дисциплинированность, ответственность за выполнение планов, заданий, добросовестность и др. [6]. В качестве бонусной программы для волонтеров предусматриваются бесплатный вход в музей, приглашения на концерты и выставки, доступ к уникальным музейным фондам и образовательным программам культурных учреждений. Бонусами становятся и специальные программы тренингов по ораторскому искусству, работе с людьми и развитию личности. Например, «Карта волонтера» Политехнического музея предусматривает бесплатное посещение выставок и лекций в течение года. За время существования Службы волонтеров были созданы схемы сотрудничества ее участников с отделами музея и определены приоритетные направления работы как в Эрмитаже, так и в других музеях.

Все вышеназванные факторы определяют приоритетные направления в работе Клуба волонтеров Приморской государственной картинной галереи и являются действенным фактором развития коммуникативных связей внутри и вне музея.

«Клуб волонтеров» в Приморской государственной картинной галерее начал свою работу в марте 2016 г. в связи с основанием будущего Центра «Эрмитаж-Владивосток», став к сегодняшнему дню неотъемлемой частью внутренней жизни музея. Каждый новый участник начинает с того, что заполняет специальную анкету, содержащую вопрос: быть волонтером в Музее престижно? Ответы на него раскрывают коммуникационный потенциал волонтеров и музея. В настоящий момент Клуб насчитывает около 50 членов, они активно участвуют в популяризации выставок и мероприятий Приморской государственной картинной галереи в своих социальных сетях и лично; ведут экскурсии, приглашая своих друзей, принимают участие в различных проектах, концертах и акциях, распространяют печатную продукцию галереи. Состав Клуба разновозрастной: студенты, пенсионеры, женщины в декретном отпуске, домохозяйки и др. Для осуществления внутренней коммуникации ежеквартально проводятся собрания Клуба, видеоконференции со Службой волонтеров Государственного Эрмитажа. Волонтеры получают право подготовить свои вопросы и получить ответ. В качестве поощрений волонтеры имеют свободный вход на выставки и мероприятия музея. Специально для них 5 декабря в Международный день волонтера проводится чаепитие, обсуждается работа Клуба, перспективы работы. Коммуникация также осуществляется в социальных сетях.

Существуют ли универсальный способ мотивации при работе с добровольными помощниками и общая цель, объединяющая волонтерское движение в мировой и отечественной музейной практике? Можно ли назвать работу музейных волонтеров элементом развития современных музейных коммуникаций и что полезного получают музеи при работе с волонтерами? Чтобы ответить на эти вопросы, необходимо рассмотреть цели и задачи, которые ставят перед волонтерами государственные музеи и иные культурные учреждения. Евгений Горькаев, учредитель волонтерской организации для помощи инвалидам «Душевный базар», процитировал самый частый вопрос, 


\section{Учёные записки}

Комсомольского-на-Амуре государственного технического университета

который ему задают новые члены волонтерского сообщества: «Что здесь происходит такого, ради чего все работают?» Можно предположить, что ответ на него является главным в вопросе идентификации волонтерского движения, в том числе в учреждениях культуры.

Очень часто работодателям приходилось сталкиваться с полным непониманием сущности волонтерской работы. Это заключалось в том, что лица, собирающиеся ее выполнять, относились к ней как к развлечению или видели в этом лишь способ получить работу или рекомендации от работодателя, не давая ничего взамен. Иногда вообще трудно понять, какие цели при этом преследуются [3].

Сегодня крупные музейные институции мира предлагают волонтерам огромное число заданий самого широкого профиля: например, попробовать себя в роли экскурсоводов, журналистов, «медиаторов», фотографов, ассистентов при проведении мероприятий и др. Продолжительность программы и локация волонтеров в музеях зависят от уровня их подготовки и предпочтений. Массовое тиражирование опыта использования труда добровольцев музеями стало следствием появления в США отдельных организаций (благотворительные центры, агентства, специализирующиеся в сфере добровольческих трудовых отношений), занимающихся вопросами трудоустройства волонтеров [2].

Эффективными методами коммуникации сегодня считаются дискуссии на темы, связанные с искусством, в которых принимают участие сотрудники музея, волонтеры и стажеры. Служба волонтеров предоставляет возможность прохождения практики студентам российских и иностранных вузов. Городские праздники расширили репертуар культурных городских практик, вовлекли новую аудиторию в культурную жизнь города и посетителей в учреждения культуры, что повлекло за собой и массовое привлечение волонтеров. Достигли огромных успехов в сфере волонтерства английские музеи: желающих работать в музеях страны на добровольных и безвозмездных началах так много, что стать волонтером можно только на конкурсной основе, пройдя значительное количество тестов и собеседований. Кроме того, практикуются листы ожидания [2].

Современные успешные практики волонтерства рассматриваются с различных точек зрения.

Григорий Сергеев, председатель отряда «Лиза Алерт» (волонтерская организация по поиску пропавших людей), рассказывает, что изначально в основе лежала общая идея. Команда создавалась на личной инициативе, на желании людей помогать пропавшим, и это важно, потому что если общая идея есть, а инициативы и жертвенности нет, то ничего с места не сдвинется. Мария Гальперина, учредитель праздничного агентства «Яркие люди», продолжает: «Но здесь территория творчества, здесь наказывать провинившихся не получится». Ольга Ребковец, руководитель проекта «Тотальный диктант», на вопрос о составе команды отвечает: «В основном штаб состоит из волонтеров, и тут важно понимать, что у большинства участников есть своя “взрослая жизнь" и практически ни для кого фонд не является основным местом работы. Все волонтеры в рамках своей профессии обладают какими-то знаниями, умениями, которыми они делятся со штабом. Это специалисты в области IT, PR, политтехнологи и др. Я являюсь руководителем проекта, но я не тот человек, который ставит задачи и требует жесткого исполнения. Координаторы, отвечающие за определенную область воздействия, сами формируют свои задачи в соответствии с компетенциями, которыми они сами обладают. И от того, как человек выстроит эту работу, зависит общий успех проекта. Конечно, я наблюдаю за общей картинкой, чтобы смысл проекта, его идеология и ценности не были утеряны. Но в целом это коллективное творчество». Евгений Горькаев, Инга Моисеева озвучивают ответ на главный вопрос новичков («Что здесь происходит такого, ради чего все работают?») так: «Например, в прошлом году пришли два девятнадцатилетних парня побыть денек волонтерами. Сначала испугались, хотели сбежать. Но, подумав, остались, а потом привели с тобой весь свой факультет. Как сочетаются ситуация, в которой нужно работать за идею (и все равны), и управление, когда нужно обеспечить ритмичное выполнение этапов общей работы? Мы призываем людей хотя бы один день провести со смыслом». «Одинаковое отношение к результату, ощущение, что тебя понимают, в конце концов приводит к тому, что мы начинаем больше общаться, можем, например, на выставку пойти вместе», - говорит Марина Евремова, одна из волонтеров [4]. 
Блаженкова Ю. П.

ВОЛОНТЕРСКОЕ ДВИЖЕНИЕ КАК ЭЛЕМЕНТ РАЗВИТИЯ СОВРЕМЕННЫХ МУЗЕЙНЫХ КОММУНИКАЦИЙ

(НА ПРИМЕРЕ БИБЛИОТЕКИ ПРИМОРСКОЙ ГОСУДАРСТВЕННОЙ КАРТИННОЙ ГАЛЕРЕИ)

Следуя неизменному принципу популяризации науки, музей превратился в настоящую научно-культурную институцию, куда ежедневно приходят посетители разных возрастов. Сегодня волонтеры могут попробовать себя в качестве консультанта по взаимодействию с новейшими музейными технологиями на площадке основной экспозиции музея или сделать свой вклад в организационную часть проекта.

Области деятельности волонтеров в музеях обширны: добровольцы могут работать в качестве ассистентов на детских мероприятиях, ассистентов на публичных событиях музея (лекциях, ворк-шопах, перфоманссах, флэш-мобах), проводить соцопросы [5]. Волонтер сам определяет время, которое может посвятить работе в музее.

Сегодня в коммуникационные задачи музея входит осуществление многоуровневого, многопространственного и многовременного взаимодействия друг с другом различных информационных потоков. Расширение связей с обществом формирует положительный имидж музея, способствует его востребованности. Развитие и поддержание в актуальном состоянии волонтерских объединений в музеях может помочь формированию у подрастающего поколения высокой нравственности, патриотизма, чувства ответственности, уважения к культуре, осознанию своего места в ней, а также созданию условий для эффективного контакта с молодежной аудиторией.

\section{ЛИТЕРАТУРА}

1. Горлова, Н. И. Исторические аспекты развития культурного волонтерства в России / Н. И. Горлова // Ученые записки. Электронный научный журнал Курского государственного университета. - 2016. № 3(39). - С. 101-108.

2. Горлова, Н. И. Современное развитие волонтерских практик в учреждениях культуры за рубежом Н. И. Горлова // Научный альманах. - 2017. - № 6-1(32). - С. 263-266.

3. Молодежное волонтерство в сфере культуры: версии существующие и перспективные [Электронный ресурс]. - Режим доступа: http://www.rgub.ru/schedule/news/item.php?new_id=5374 (дата обращения 18.01.2018).

4. Командный дух: технология. Как на Руси строить хорошее дело / И. Найденов, А. Маглыш, О. Тимофеева-Глазунова, М. Антонова // Русский репортер. - 2017. - № 19. - С. 15-25.

5. Плюсы и минусы волонтерства [Электронный ресурс]. - Режим доступа: http://www.newca.com/doc/n.aspx?28\&4 (дата обращения 16.01.2018).

6. Рябкова, Н. И. Волонтерское/добровольческое движение в Зауралье: Щадринский волонтерский корпус 70-летия Победы / Н. И. Рябкова // Волонтер. - 2016. - № 3(19). - С. 21-57. 